\title{
4 \\ Does Public Policy Obey Data, Information and Maps?
}

\author{
Stephen Dovers
}

\section{Key Points}

- The link between science (maps and data) and policy is complex and variable: rarely strong and direct; sometimes discernible and positive; often hard to discern or sadly missing. Other things matter as well in political decisions.

- Australia has enviable capacities in land use science, as this volume shows, and although the application of this science may disappoint, our situation would be far worse without this excellent knowledge base.

- Lack of continuity of data and initiatives is a major issue for rational and sustainable land use decision making.

- A better understanding of science by policy makers, and of the realities of policy and politics by scientists, could improve the situation.

Endless data, information and maps instruct us that Australia-and indeed the world - should be doing considerably more than is being done to ensure the sustainable use of natural resources, both in the interests of the inherent value of natural ecosystems and the future wellbeing of human populations (e.g. Lindenmayer et al., 2014; United Nations, 2012; United Nations Environment Programs, 2012). The information base is 
not equivocal—species and ecosystems are being lost at an alarming rate, the natural resource base of too many societies is being degraded at an unsustainable rate, the stability of climate is being disturbed, and the capacity of natural systems to absorb our waste is regularly exceeded.

As the chapters in this volume show, Australia is a leader in environmental data gathering. It is also a leader in the transformation of such data into models, maps and indicators that are suited to use by land managers and policy agencies. Yet, the scientists involved generally regard the use and effect of this knowledge base as insufficient.

Why don't local, national and international policymakers obey the messages from 'science', ${ }^{1}$ implement appropriate policies in a rational manner and address the problems more purposefully? Some people, including many scientists and economists, believe that politics and policy should be entirely rational, taking on board expert evidence and enacting policies that address manifest problems. In the discipline and practice of public policy, this fantasy was abandoned long ago (see Dovers \& Hussey, 2013). The processes that determine public policy are not, and can never be, linear and rational. There is too much at stake and too many competing interests to be considered: ecosystem integrity, poverty alleviation, maintenance of employment, social values and public support, international policy commitments, competition for available funding, public policy effort and more. Of course, politics can be messy, bloody, divisive and myopic. For the moment, we can take the scientific and official international policy consensus that the current answer is not nearly enough.

There are counter cases, as evidenced by the many decisions made to protect the environment and to use natural resources more judiciouslypolicy decisions about pollution, endangered species, water abstraction, ozone-depleting substances and so on. Australia’s protected areas network has increased by an order of magnitude over the course of the last century; this has been informed by ecological science findings describing the decline of native species and loss of ecosystems, among other influences. Similarly, Australia's world-leading experiments in connectivity conservation owe much to Australia's world-leading landscape ecology. The landmark 1975-77 collaborative federal-state soil conservation

1 I use the term 'science' broadly to mean the information emerging from the natural sciences (ecology, physics, hydrology, etc.), but also social science disciplines (demography, economics, sociology, etc.). When differentiation is needed, it will be apparent. 
study, and its later transformation into maps (see Woods, 1983), was fundamental to the Decade of Landcare initiative and what followed in national policy. However, science never operates alone. That land degradation data and mapping exercise was important, but so too was the genius of an alliance between the National Farmers Federation and the Australian Conservation Foundation. Led by Rick Farley and Phillip Toyne, it had the support of prime minister Robert Hawke, an advocate of consensus who was ready to seize the moment. The dramatic erosionfuelled dust storm over Melbourne that filled the television screens of urban Australians (who were usually unaware of non-metropolitan issues) was also important, as was the experience of programs and practices built up over decades by the various state soil conservation agencies. Science, politics, practical agency knowledge and opportune media moments combined to create interest in the environment.

Why has environmental action not followed (or been perceived to follow) environmental science more closely? The answer is at once simple and highly complex. The simple answer is that 'science'-environmental or otherwise-is only one of several information inputs to policy: other messages matter too, whether one agrees that they should or not. The complex answer is that the story of how policy is made and implemented, and what information and imperatives influence it, varies enormously from issue to issue, jurisdiction to jurisdiction and over time. There are no strict rules or predictable patterns. To make some sense of this complexity within the context of this volume, this chapter briefly presents some key concepts and frameworks from the discipline of public policy, illustrated with examples from the natural resources and environment domains. This will be done in two parts: evidence-based policy and information in policy.

\section{What is the 'Evidence' in Evidence-Based Policy?}

There is an expectation that the policy decisions of governments, made after consultation and interaction with partners from the private and community sectors, will be based on solid, rigorous information and analysis. In recent years, the term (and aspiration of) 'evidence-based' policy has become commonplace. This raises an important question: 
what 'evidence' is required to fulfil the modern promise of evidence-based policy? Head (2008) defined three forms of evidence that are called upon when policy is made:

1. systematic ('scientific') research

2. program management experience ('practice')

3. political judgement.

This simple but defensible schema places environmental science in context; and it certainly played out in the soil and land degradation case described above. In the domain of land use and environmental management, 'scientific' research and information is not only one of three forms of evidence, but also includes more than ecology and landscape science and the like-it also incorporates economics, sociology, demography and more. The 'scientific' consensus of what should be done-assuming there is one (often there is not) — may be rather divided depending on what value or asset, and thus what discipline, is the priority. Can we quantitatively and scientifically trade-off threatened species, groundwater aquifers, rural employment and legal obligations under international trade and other agreements? This is when the other two categories of evidence come into play: policymakers and advisors must determine whether a path of action is practically achievable or advisable in a public policy sense, and whether governments and the public are likely to accept it. Davis, Wanna, Warhurst and Weller (1993) summed up the political reality:

Politics is the essential ingredient for producing workable policies, which are more publicly accountable and politically justifiable ... While some are uncomfortable with the notion that politics can enhance rational decision-making, preferring to see politics as expediency, it is integral to the process of securing defensible outcomes. We are unable to combine values, interests and resources in ways which are not political. (p. 257)

Policy directions are set by governments; they reflect an interpretation of social goals and always involve 'value, interests and resources'-matters that are beyond linear, rational scientific answers. Policymaking is a social and political process; like politics itself, it is sometimes short-sighted, combative and disorderly. For example, after an unprecedentedly rigorous investigation, the Resource Assessment Commission (RAC) reported that a proposed uranium mine at Coronation Hill was economically valuable, environmentally problematic (but manageable) and damaging to Indigenous culture (Stewart \& McColl, 1994). Whether the mine 
should go ahead could not be quantified or rendered to a composite metric that provided the yes-or-no answer wanted by some, for this required a value judgement-a political judgement. While researchscientific inquiry, data gathering and analysis—could enable and inform that judgement, it was up to politicians to make it-specifically, federal cabinet. Internationally remarkable, the RAC linked expertise and evidence with public policymaking and broke new ground in methods and processes; however, it lasted only four years. Embroiled in near-term, politically sensitive issues, its rigorous 'scientific' interpretations probably contributed to its demise. Science (and economics and social science, in the Coronation Hill case) can get too close to policy and politics.

That leads to the first, crucial point of this chapter. In a liberal democracy, policy is not (and never will or should be) made by 'experts'; rather, it is made by politicians and governments, reflecting social values and aspirations. Rob Lesslie's foundational work on wilderness (see Chapter 1) did not make policy: societal values had shifted towards valuing wilderness, and government wished to follow this shift. Rob's work provided a robust evidence base from which sound decisions could be made.

\section{How Does Policy Use Information?}

Confining ourselves to Head's 'systematic research' as an input to policy, we can consider different ways in which information or evidence might be used in policy. Sometimes direct utilisation and impact occurs, leading to a discernible policy change. However, this does not occur very often, for not only do other forms of 'evidence' matter, but information can also be put to positive use, used negatively or simply ignored. Applying longdiscussed (and contested) concepts from theoretical and practical public policy literature to composite environment and sustainability indicators, Hezri (2004) identified five forms of information utilisation in policy: instrumental, conceptual, symbolic, tactical and political. He mapped these against the nature of the response to information and the degree of rationality of use, as shown in Table 4.1. 
Table 4.1: Taxonomy of indicator (information) use.

\begin{tabular}{|l|l|l|}
\hline Nature of response & High degree of rationality & Low degree of rationality \\
\hline Positive & Instrumental use & Political use \\
\cline { 2 - 3 } & $\begin{array}{l}\text { Accepted and used to direct } \\
\text { or inform policy choice or } \\
\text { design. }\end{array}$ & $\begin{array}{l}\text { Used to support a predetermined } \\
\text { policy position, not necessarily } \\
\text { with any concern over quality. }\end{array}$ \\
\hline Ordinary & Conceptual use & Symbolic use \\
\cline { 2 - 3 } & $\begin{array}{l}\text { Information 'seeps into' policy } \\
\text { discourse, reframing, with a } \\
\text { subtle impact over time. Can } \\
\text { define the policy agenda. }\end{array}$ & $\begin{array}{l}\text { Used to assure other parties that } \\
\text { something is being done; the } \\
\text { situation is being considered. }\end{array}$ \\
\hline Negative & Not used & Tactical use \\
\cline { 2 - 3 } & $\begin{array}{l}\text { Information discarded or } \\
\text { disregarded. }\end{array}$ & $\begin{array}{l}\text { Incomplete information, or further } \\
\text { information gathering, used to } \\
\text { delay decisions, as a substitute } \\
\text { for action, or to deflect criticism. }\end{array}$ \\
\hline
\end{tabular}

Source: Adapted from Hezri (2004).

Consider any major contested issue, past or present, and information will have been 'used' in more than one of the ways defined in Table 4.1: to support or oppose some policy action, or to deflect criticism or defer a decision. It may have been contested; it may have been ignored. While evidence of clear instrumental use is unusual, the argument for conceptual use is much stronger; however, it is a diffuse phenomenon to trace and attribute.

Instrumental or direct use should not be overinterpreted. It is very rare that science directly drives or determines research, but it may well be an important reference point or input (e.g. Rob Lesslie's wilderness work). Major scientific efforts have been behind the setting of sustainable diversion limits and environmental water allocations in the MurrayDarling Basin; however, expert consensus did not determine the final number: the science informed, but did not determine the policy outcome. Is 2,750 gigalitres too little or too much? The answer is a matter of science; it is also a matter of normative values and competing imperatives.

Science can influence policy agendas in different ways and sometimes gains purchase by narrowing the focus of policy attention. The integration of an array of issues-including soil erosion, rangeland vegetation decline, acidification, soil structural decline and salinity-into the one agenda of land degradation by Woods (1983) and others was a major advance in understanding and conceptualisation. However, driven by 
environmental scientists, this agenda was quickly dominated by dryland salinity. Acidification, erosion and structural decline were still there, but we stopped talking about them, and funding and policy faltered. Perhaps we can only twiddle one knob at a time? In the 1980s, Australia began to embrace the United States' lead and agenda regarding 'instream flows', a package of non-extractive values of water in situ in rivers, including ecological, recreational, aesthetic and cultural values, and geomorphic integrity. The Australian discourse and policy direction restricted rapidly towards ecological values and adopted the term 'environmental flows'; this move reduced the evidentiary power of non-extractive water values and alienated those for whom an 'environmental' agenda was not attractive.

When 'science' sets the policy agenda, or has a distinct impact, it may be that only one set of opinions, disciplines or findings is in play. Scientists from the same discipline or even subdiscipline are often called upon as expert witnesses by opposing sides of legal battles, and disagree superbly. Which 'scientist' should a policymaker or a judge believe, and why? What standard of proof must they display to earn such belief?

\section{Uncertainty and Standards of Proof}

Arguably, the natural sciences are more cautious in the face of uncertainty than others engaged in policy debates: 95 per cent confidence limits are a high standard, and anonymous peer review is, for all its occasional faults, a rigorous process. In some science-to-policy instances, there is an agreed nomenclature describing uncertainty and confidence (the nomenclature used by the Intergovernmental Panel on Climate Change being the most famous), but often there is not. However, different confidence limits used in science are only part of the story. Does 95 per cent equate to the criminal law's 'beyond reasonable doubt'? Is it certainly higher as a standard of evidence than the civil law's 'on the balance of probabilities'? Does the civil law standard equate to the public policy theory and practice of 'satisficing'? How does a seasoned policy official assess the probability of gaining approval for a proposal from the relevant minister and cabinet? While such an assessment may draw on 'systematic (scientific) research', being the first of Head's three lenses, it would rely more heavily on 'program management experience' and 'political judgement'. What standard of proof is used, either implicitly or explicitly, by other actors in the environment domain: the media, consultants doing an environmental impact statement, industry and union officials defending 
jobs, professional environmental lobbyists, or local residents opposed to coal seam gas developments? Two real but anonymised exchanges illustrate the difference:

1. In a discussion around identifying wildlife corridor (connectivity conservation) projects that are of significance:

Senior scientist: 'I'm wary of lines on the maps ... the uncertainties around definite boundaries and around which projects would be the most effective for conservation are too great'.

Senior government official: 'Well if you won't I'll get a bloody big thick texta and do it myself'.

2. Presenting a predictive urban land surface mapping method drawn from remote-sensed data:

Spatial scientist: 'This hasn't really worked ... ground truthing is only getting us to about 80 per cent accuracy'.

Urban planner: ' 80 per cent: that's luxury! Anything near 60 and we take it on board in future planning'.

A lack of understanding of different standards of proof and ways of presenting evidence is rife. Many people outside research do not understand the scientific method, confidence limits or peer review. Equally, many scientists (and social scientists) do not understand how public administration, public policy, the courts and politics function. The situation is made worse by tactical, symbolic and political uses of information in public debates, and by the inability (or refusal) of the media to convey complexity, uncertainty and the nature of 'systematic (scientific) research'. There is much discussion of how mutual understanding could be improved: science communication, cross-institutional secondments, citizen science, new forms of media (e.g. The Conversation), knowledge brokers and boundary organisations, and whole journals devoted to the interface (e.g. Environmental Science and Policy). However, for those scientists close to the game and concerned with engaging with policy, I have a simpler and quicker suggestion: read a policy textbook and at least know some of the landscape and terminology-I recommend Dovers and Hussey (2013).

A final observation on uncertainty (or an indulgent diversion to make a point). There is, of course, no standard of proof or evidence rule that can be applied to policy proposals; they vary too much in their substance and 
implications. To give a crude illustration: a land use or production change driven by strong evidence of environmental damage that would lead to 50 job losses will always be judged differently to one that would cause 500 job losses. The stakes matter and the trade-offs will always be evaluated through the policy and political process. The precautionary principle instructs care in the face of 'serious or irreversible' environmental harm; this is something we can generally comprehend-loss of topsoil, extinction of a species or poisoning a slow-moving aquifer. Can we turn the 'irreversibility' test against policy as part of the conversation around standards of proof and trade-offs (Dovers, 2006)? Just as some environmental damage cannot be reversed, the same can also be said for policy decisions: consider privatising a natural resource management function, changing property rights or discontinuing, for even a few years, an environmental data time series. Given that it is extremely rare that a policy can be guaranteed to have a specific impact, thus 'satisficing' a reasonable standard of proof or evidence, should a policy or institutional change that cannot be (or cannot easily be) reversed be subject to a higher standard-perhaps even beyond reasonable doubt?

\section{Conclusion}

Does policy obey data, information and maps? This brief chapter repeats the standard public policy answer: sometimes a bit, sometimes a lot and sometimes not at all. This may be an unsatisfying answer for many people who wish for rational, science-based decisions to be standard; however, hopefully, the answer is at least more comprehensible when the nature of evidence and information use in policy is explained.

To end on an untestable but mildly optimistic point: Australia is home to world-class environmental and landscape science; scientists are often engaged closely with policy and land management agencies and there is some evidence of their impact. They may be frustrated that not all decisions and practices are consistent with their evidence, but they might want to consider how Australia's natural resources and ecosystems would be faring without them. 


\section{References}

Davis, G., Wanna, J., Warhurst, J. \& Weller, P. (1993). Public policy in Australia. Sydney, NSW: Allen \& Unwin.

Dovers, S. (2006). Precautionary policy assessment for sustainability. In E. Fisher, J. Jones \& R. von Schomberg (Eds.), Implementing the precautionary principle: Perspectives and prospects (pp. 88-109). Cheltenham, UK: Edward Elgar. doi.org/10.4337/9781847201676. 00014

Dovers, S. \& Hussey, K. (2013). Environment and sustainability: A policy handbook (2nd ed.). Sydney, NSW: Federation Press.

Head, B. (2008). Three lenses of evidence-based policy. Australian Journal of Public Administration 67, 1-11. doi.org/10.1111/j.14678500.2007.00564.x

Hezri, A. A. (2004). Sustainability indicator system and policy processes in Malaysia: A framework for utilisation and learning. Journal of Environmental Management 73, 357-71. doi.org/10.1016/j. jenvman.2004.07.010

Lindenmayer, D. B., Dovers, S. \& Morton, S. (Eds.). (2014). Ten commitments revisited (2nd ed.). Melbourne, VIC: CSIRO Publishing.

Stewart, D. \& McColl, G. (1994). The Resource Assessment Commission: An inside assessment. Australian Journal of Environmental Management 1, 12-23.

United Nations. (2012). The future we want: Rio +20 United Nations conference on sustainable development, outcomes of the conference. New York, NY: United Nations. Retrieved from www.un.org/en/ sustainablefuture/

United Nations Environment Programs. (2012). Global Environment Outlook GEO5: Environment for the future we want. Nairobi, Kenya: United Nations Environment Program.

Woods, L. E. (1983). Land degradation in Australia. Canberra, ACT: Australian Government Publishing Service. 
This text is taken from Land Use in Australia: Past, Present and Future, edited by Richard Thackway, published 2018 by ANU eView, The Australian National University, Canberra, Australia.

doi.org/10.22459/LUA.02.2018.04 